None of them had a history suggestive of tropical spastic paraparesis, the other known syndrome associated with HTLV-1 infection. Our patient was a second generation immigrant from south China. She had never travelled to HTLV-1 endemic areas, but had received a blood transfusion for post-partum haemorrhage during delivery of her first child.

\section{Comment}

HTLV-1 infections have not been widely documented in east Asia outside of Japan and Taiwan. The seroepidemiological pattern of this infection in South East Asia has not been well studied. A recent serological survey of 9689 healthy blood donors and pregnant women in Singapore showed an incidence of $0.03 \%$ (unpublished data). This is close to the $0.025 \%$ seroprevalence documented in blood donors in the United States. ${ }^{4}$

The fact that both vertical and horizontal transmission of this infection can readily occur is well illustrated by this case. This ease of transmission is of concern, especially when pockets of HTLV-1 infection have been documented in unusual areas. ${ }^{5}$ At the least, seroepidemiological trends must be monitored to ensure that the problem does not take on greater proportions.
The low seroprevalence of HTLV-1 in non-endemic areas is likely to preclude costeffective screening of blood donors. Patients with mature T-cell lymphoid malignancies, however, should be screened for infection. Contact tracing after identification of the index case is likely to be fruitful. The detection of infected patients, together with counselling on the modes of transmission, may help to prevent further transmission and protect national blood resources. We thank Dr T P Y in of the Specialist Centre in Penang for
his cooperation. This work was supported in part, by the his cooperation. This work was supported in part, by the
National University of Singapore Biological Sciences Research National University
Project RP 890383.

1 Levine PH, Blattner W, Clark J, et al. Geographic distribution of HTLV-1 and identification of a new high-risk population. Int $J$ Cancer 1988;42:7-12.

2 Suchi T, Lennert K, Tu LY, et al. Histopathology and immunohistochemistry of peripheral T cell lymphoma: a proposal for their classification. J Clin Pathol 1987;40: 995-1015.

3 Sakuma M, Takiguchi T, Konda S. HTLV-1 carriers in ATLL-nonendemic area with reference to blood transfusions. Nippon Ketsueki Gakkai Zasshi 1989;52:869-79.

4 Williams AE, Fang CT, Slamon D, et al. Seroprevalence and epidemiologic correlates of HTLV-1 infection in US blood donors. Science 1988;240:643-6.

5 Weber J. HTLV-1 infection in Britain. Official recognition of the need for surveillance is overdue. $\mathrm{Br} \mathrm{Med} \mathrm{J} \mathrm{1990;}$ 301:71-2.

\title{
Treatment of acute myeloid leukaemia in a renal allograft recipient: Implications of cyclosporin immunosuppressive treatment
}

\author{
R J G Cuthbert, N H Russell, P A E Jones, A G Morgan
}

Department of

Haematology, City

Hospital, Nottingham

NG5 1PB

R J G Cuthbert

N H Russel

P A E Jones

Department of Renal

Medicine

A G Morgan

Correspondence to:

Dr R J G Cuthbert

Accepted for publication

12 February 1991

\begin{abstract}
The clinical effects of cyclosporin were evaluated during cytotoxic treatment in a 61 year old man with acute myeloid leukaemia. He had required a renal transplant 18 months before presenting with acute myeloid leukaemia (FAB subtype M4). He had received cyclosporin $3.5-4.0 \mathrm{mg} / \mathrm{kg}$ daily to maintain a plasma cyclosporin concentration of 75-150 ng/ ml. Cyclosporin was continued during induction chemotherapy with daunorubicin, cytarabine, and 6-thioguanine (DAT). He had fever and oropharyngeal candidiasis that was unresponsive to anti-bacterial drugs but responsive to systemic amphotericin. Bone marrow examination 14 days after chemotherapy showed complete haematological remission. Subsequently he tolerated consolidation treatment with DAT with no
\end{abstract}

serious complications. Unfortunately he developed fatal septicaemia following a second consolidation with mitozantrone and cytarabine.

Inhibition of P-glycoprotein activity by cyclosporin may not significantly increase the toxicity of aggressive chemotherapeutic regimens, and as benefit may be achieved by this approach further clinical evaluation is justified.

In the management of malignant disease resistance to cytotoxic drugs often makes treatment unsuccessful. Interest has developed in studying the possible benefits of inhibiting the activity of P-glycoprotein to circumvent cytotoxic drug resistance. ${ }^{1} \mathrm{P}$-glycoprotein is a 170 kilodalton transmembrane glycoprotein which acts as an energy dependent pump, causing active efflux of structurally hetero- 
geneous substances, including daunorubicin and vincristine, from cells. It is encoded by the MDR-1 gene. The multidrug resistant phenotype is characterised by overexpression of P-glycoprotein. This can be recognised in several malignancies including acute myeloid leukaemia (AML). ${ }^{2}$ In AML it occurs most frequently in relapse following previous heavy cytotoxic exposure. Excessive expression results in inadequate intracellular concentrations of cytotoxic drugs such as daunorubicin, and consequent resistance to chemotherapy.

Drugs including verapamil, quinine, cyclosporin, and calmodulin inhibitors inhibit $P$ glycoprotein activity, and some of these agents are being evaluated as adjuncts to cytoxic chemotherapy in malignancies associated with the multidrug resistant phenotype. Many normal tissues, including gastrointestinal mucosa, pancreatic and biliary tracts, adrenal glands, renal tubular cells and alveolar cells, express P-glycoprotein. There is therefore, a theoretical potential for increased nonhaemopoietic toxicity by inhibition of the efflux of cytotoxic drugs from normat cells. This might be manifested-for example, by increased severity and duration of gastrointestinal mucositis, pulmonary defects, and impaired renal function.

Haematological chart of patient with renal allograft treated for $A M L$ showing changes following chemotherapy with $D A T$ $3+10,2+7$, and Mid $A C$.

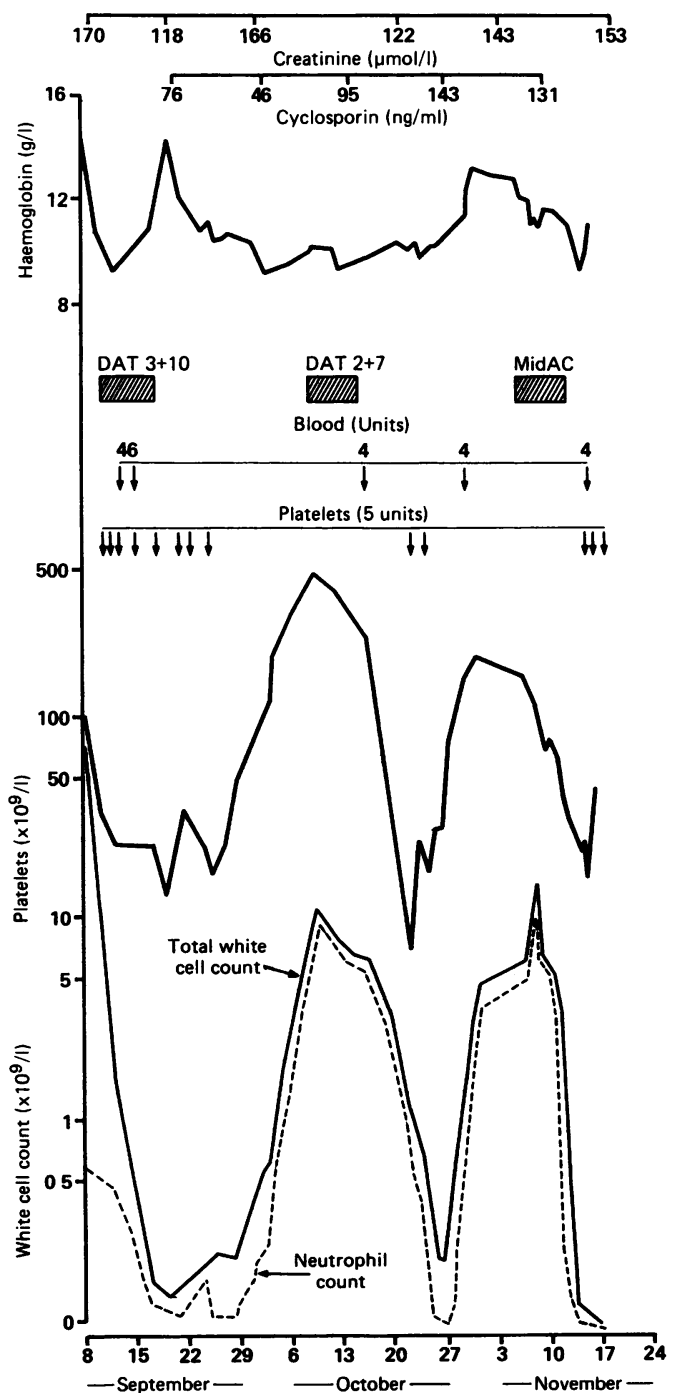

\section{Case report}

In March 1988 a 61 year old man received a cadaver renal allograft for end stage polycystic disease. He was treated with cyclosporin 3.5$4.0 \mathrm{mg} / \mathrm{kg}$ daily and prednisolone $10 \mathrm{mg}$ daily. The plasma cyclosporin concentration was maintained in the range $75-150 \mathrm{ng} / \mathrm{ml}$.

In September 1989 he developed malaise and fever. The peripheral blood count showed a white cell count of $79 \times 10^{9} / 1$ with $95 \%$ blasts. The bone marrow showed $80 \%$ AML blasts (M4) with suppression of normal haemopoiesis. Cytogenetic analysis showed a normal $46, \mathrm{XY}$ karyotype. He was treated with daunorubicin $50 \mathrm{mg} / \mathrm{m}^{2}$, for three doses on alternate days, cytarabine $100 \mathrm{mg} / \mathrm{m}^{2}, 12$ hourly, and 6thioguianine $100 \mathrm{mg} / \mathrm{m}^{2}, 12$ hourly, for 10 days (DAT $3+10)$. He continued to receive cyclosporin $3.5-4.0 \mathrm{mg} / \mathrm{kg}$ daily and prednisolone $10 \mathrm{mg}$ daily throughout treatment. His fever was unresponsive to anti-bacterial drugs. $\mathrm{He}$ developed moderately severe oropharyngeal candiadiasis which did not respond to topical antifungal treatment. He was given intravenous amphotericin $0.6 \mathrm{mg} / \mathrm{kg}$ daily with a good clinical response. Bone marrow examination two weeks after chemotherapy showed complete haematological remission.

Subsequently he received two courses of consolidation chemotherapy: daunorubicin $50 \mathrm{mg} / \mathrm{m}^{2}$ for two doses on alternate days, cytarabine $100 \mathrm{mg} / \mathrm{m}^{2}, 12$ hourly and 6thioguanine $100 \mathrm{mg} / \mathrm{m}^{2}, 12$ hourly, for seven days (DAT $2+7$ ). This was followed after one month by cytarabine $1 \mathrm{~g} / \mathrm{m}^{2}, 12$ hourly, for three days and mitozantrone, $10 \mathrm{mg} / \mathrm{m}^{2}$ daily, for five days (MidAC). The figure shows the haematological and renal responses to chemotherapy. There were no clinical complications following DAT $2+7$. After MidAC, however, while severely neutropenic, he developed Pseudomonas aeruginosa septicaemia, and despite aggressive antibiotic and supportive treatment he died from acute renal failure and adult respiratory distress syndrome.

\section{Discussion}

Myelodysplasia and acute myeloid leukaemia have been described in renal allograft recipients treated with azathioprine. ${ }^{3-7} \mathrm{We}$ know of only one previous report of the development of acute myeloid leukaemia in such patients receiving cyclosporin. ${ }^{8}$ This patient had also received azothiaprine. One further unpublished case is cited in this report. Our patient had been given immunosuppressive treatment with cyclosporin for 18 months before the onset of acute myeloid leukaemia. Although a causal relation between his relatively short duration of immunosuppression and the subsequent development of acute myeloid leukaemia seems unlikely, the possibility cannot be excluded.

Remission induction was achieved relatively easily in our patient. There was no evidence that his concurrent cyclosporin treatment cused increased toxicity to normal tissues or to his grafted kidney. This suggests that inhibition of P-glycoprotein with drugs such as 
cyclosporin may not greatly increase the toxicity of aggressive chemotherapy used in the treatment of haematological malignancies. Sonneveld and Nooter reported a patient with resistent AML to whom they administered cyclosporin without any excessive toxicity, although their patient had profound marrow hypoplasia for three weeks. ${ }^{9}$

Septic shock is a well recognised problem in severely neutropenic patients. It is difficult to be sure that our patient's clinical course would have been any different had he not received cyclosporin. Although cyclosporin and other inhibitors of $\mathbf{P}$-glycoprotein may improve the response to chemotherapy, the use of immunosuppressive agents during the treatment of acute myeloid leukaemia does require caution. Non-immunosuppressive cyclosporin analogues may produce the desired positive effects of P-glycoprotein inhibition without increased infection risk. ${ }^{10}$
1 Anonymous. Multidrug resistance in cancer. [Editorial]. Lancet 1989;ii:1075-6.

2 Holmes J, Jacobs A, Carter G, et al. Multidrug-resistance in haemopoietic cell lines. Myelodysplastic Syndromes and acute myeloblastic leukaemia. Br J Haematol 1989;72: 40-4.

3 Case records of the Massachusetts General Hospital. Weekly clinico-pathological exercises. Case 18-1983. A young man with pancytopenia after a renal transplant. $N$ Engl J Med 1983;308:1081-91.

4 Ellerton JA, deVeber GA, Baker MA. Erythroleukaemia in a renal transplant recipient. Cancer 1979;43:1924-6.

5 Pikler GM, Say B, Stamper S. Cytogenetic findings in acute monocytic leukaemia in a renal allograft recipient. Cancer Genet Cytogenet 1986;20:101-7.

6 Hoy WE, Packman CH, Freeman RB. Evolution of acute leukaemia in a renal allograft recipient:? Relationship to azathioprine. Transplantation 1982;33:331-3.

7 Ihle BU, Constable J, Gordon S, Mahony JF. Myelodysplasia in cadaver renal allografts: A report of four cases. Am J Kidney Dis 1985;5:251-7.

8 Butler J, Korb S, Light L. Acute myelogenous leukaemia in a renal allograft recipient receiving cyclosporine therapy. Transplantation 1990;49:813-15.

9 Sonneveld $P$, Nooter $K$. Reversal of drug-resistance by cyclosporin-A in a patient with acute myelocytic leukaemia. Br J Haematol 1990;75:208-11.

10 Twentyman PR, Fox NE, White DJG. Cyclosporin A and its analogues as modifiers of adriamycin and vincristine resistance in a multidrug resistant human lung cancer cell line. Br J Cancer 1987;56:55-7.

\section{Inhibition of urease activity but not growth of Helicobacter pylori by acetohydroxamic acid}

\author{
Division of \\ Gastroenterology and \\ Department of \\ Laboratory Medicine, \\ McMaster University \\ Medical Centre, 1200 \\ Main Street West, \\ Hamilton, Ontario \\ L8N 3Z5, Canada \\ J Goldie \\ $S$ Jalali \\ $\mathrm{H}$ Richardson \\ R H Hunt \\ Division of \\ Gastroenterology, \\ Dalhousie University, \\ Victoria General \\ Hospital, Halifax \\ SJO Veldhuyzen van \\ Zanten \\ Correspondence to: \\ J Goldie \\ Accepted for publication \\ 12 February 1991
}

\begin{abstract}
The in vitro effects of acetohydroxamic acid (AHA), a potent urease inhibitor, were studied to determine the effect on the urease activity and growth of 38 strains of Helicobacter pylori. AHA in concentrations of $50-1000 \mathrm{mg} / 1$ had a noticeably reversible inhibitory effect on the urease activity of the organism but no effect on growth.
\end{abstract}

Helicobacter pylori has a very high urease activity which is thought to be related to its pathogenicity, allowing it to colonise and survive in the harsh gastric environment. ${ }^{1}$

There is a need for a more effective treatment against $H$ pylori because currently available treatments are unsatisfactory. ${ }^{2}$ Acetohydroxamic acid (AHA) is a potent inhibitor of the enzyme urease..$^{3-6}$ AHA has been used in the treatment of urinary tract infections, associated with struvite stone formation, in which urea splitting organisms are important. ${ }^{7}$ AHA prevents alkalinisation of the urine by inhibiting urease, thus preventing hydrolysis of urea and subsequent production of ammonia.

The high urease activity of $H$ pylori might be inhibited by AHA and we therefore studied this in vitro to determine whether AHA inhibits urease activity and the growth of $H$ pylori.

\section{Methods}

Thirty three recent clinical isolates and five reference strains (obtained from LCDC, Ottawa) of $H$ pylori were grown microaerobically at $35^{\circ} \mathrm{C}$ for five days. Dense suspensions were made in $3 \mathrm{mmol}$ monobasic sodiumphosphate buffer $\left(\mathrm{NaH}_{2} \mathrm{PO}_{4}\right)$ containing a concentration of AHA to approximate a final concentration of $10^{8}$ organisms $/ \mathrm{ml}$ when 